\title{
Mind Map Kolaboratif Memanfaatkan Groupware Berbasis Cloud Storage
}

\author{
Wenty Dwi Yuniarti \\ Jurusan Fisika Fakultas Saintek UIN Walisongo Semarang
}

\begin{abstract}
Abstrak
Groupware adalah aplikasi atau perangkat lunak komputer yang dirancang untuk mendukung kolaborasi dari beberapa pengguna (Alan Dix dkk, 2004: 663). Saat ini groupware berkembang, bukan sekedar sebagai perangkat lunak multi user yang dapat mengakses data sama, berbagi dokumen atau rich-media, namun dengan teknologi cloud storage, groupware mendukung penyimpanan dokumen secara online sebagai artifak atau hasil kerja kolaboratif.

Dalam pembelajaran, kolaborasi diwujudkan dengan kelompok atau kelompok kecil siswa, berinteraksi, terkoordinasi dan memungkinkan mengeksplorasi secara bersama suatu permasalahan atau tugas bermakna dalam semua fungsi proses pembelajaran. Salah satu elemen penting dalam fungsi proses pembelajaran adalah ketrampilan siswa dalam mengorganisasikan pengetahuan dan informasi. Ada beberapa cara yang dapat dilakukan guru dalam menfasilitasi tumbuhnya ketrampilan tersebut. Selain teknik mencatat, pendekatan mind map tau peta pikiran dapat digunakan menfasilitasi siswa dalam pengorganisasian informasi sehingga mempermudah pemahaman siswa atas suatu topik yang berjumlah banyak dengan waktu terbatas. Cara baru yang lebih modern dalam menfasilitasi pengorganisasian informasi adalah menggunakan groupware.

Kajian ini membahas pemanfaatan groupware MindMup 2.0 untuk mengorganisasikan pengetahuan topik cabang ilmu elektronika menurut aturan Law of Mind Map, dilakukan dalam kelompok kecil, dalam pembahasan ini dilakukan oleh empat siswa, dilakukan secara kolaboratif, sinkronous, tanpa friksi (zero friction) dengan dukungan teknologi cloud storage, Google Drive.
\end{abstract}

Kata kunci:

kolaboratif, mind map, groupware, sinkronous, Mind Map 


\section{PENDAHULUAN}

Dalam Social Development Theory of Learning, Lev Vygotsky dalam Elizabeth M.R (1999) menyatakan bahwa proses sosial mempengaruhi proses belajar individu. Dalam implementasinya, Vygotsky mendorong perubahan tradisi belajar dari sekedar transformasi pengetahuan dari guru kepada individu/siswa kepada keadaan dimana siswa memainkan peran penting sehingga harus aktif dalam pembelajaran. Vygotsky fokus pada hubungan antar individu dimana mereka berinteraksi dan berbagi pengalaman. Vygotsky percaya bahwa interaksi sosial adalah bagian dari perkembangan sosial yang mengarah pada perkembangan kognitif, artinya dalam konteks pembelajaran, individu akan mendapatkan pengetahuan atau akan dapat melaksanakan tugas bila mendapat bimbingan orang yang lebih tahu, lebih dewasa atau guru dan dengan berkolaborasi bersama teman sebaya.

Dalam pembelajaran, Calfee dkk (2004) menyebutkan ketrampilan siswa dalam mengorganisasikan pengetahuan atau informasi (organizing) merupakan salah satu elemen penting dari kesatuan fungsi proses pembelajaran (connecting, organizing, reflecting dan extending). Informasi penting bagi pembentukan ilmu pengetahuan dan siswa perlu belajar tentang bagaimana mengatur dan mengelola informasi yang diterimanya dalam pembelajaran.

Ada beberapa cara menfasilitasi siswa dalam mengorganisasikan informasi, salah satunya menurut Calfee dkk (2004), guru dapat meminta siswa melakukan pengorganisasian secara grafis melalui teknik mencatat yaitu penulisan informasi dengan tangan, baik sebelum, selama atau sesudah belajar. Calfee dkk (2004) menambahkan bahwa secara teknis, proses pengorganisasian informasi tersebut dapat dilakukan secara mandiri, kelompok kecil atau kelompok besar.

Berbeda dengan teknik mencatat, Tony Buzan (1993), seorang ahli otak dan pembelajaran, menciptakan pendekatan lain dari proses pengorganisasisan informasi melalui mind map atau peta pikiran. Menurut Buzan, 
"Mind map is a powerful graphics technique which provides a universal key to unlock the potential of the brain. It harnesses the full range of cortical skills - word, image, number, logic, rhythm, colour and spasial awareness - in single, uniquely powerful manner (Buzan, 1993: )“.

Dalam beberapa penelitian disebutkan bahwa mind map efektif digunakan untuk pengorganisasian informasi, seperti dalam penelitian Hanifah (2015) yang menyimpulkan bahwa mind map dapat digunakan untuk meningkatkan kemampuan penalaran dan penguasaan konsep. Berbeda dengan catatan konvensional yang ditulis dalam bentuk catatan linier, panjang ke bawah, teknik mind mapmerupakan teknik mencatat tingkat tinggi yang memanfaatkan keseluruhan otak, yaitu otak kiri dan otak kanan. Belahan otak kiri berfungsi menerapkan fungsi-fungsi logis yaitu bentuk-bentuk belajar yang langkah-langkahnya mengikuti urutan-urutan tertentu sehingga otak menerima informasi secara berurutan. Sedangkan otak kanan cenderung lebih memproses informasi dalam bentuk gambar-gambar, simbol-simbol, dan warna.

Selain teknik mencatat dan mind map, teknologi menawarkan cara yang lebih modern dalam pengorganisasisan informasi melalui perangkat lunak kolaboratif atau Collaborative Software atau groupware. Selain bersifat paperless, groupware bersifat kolaboratif. Groupware dirancang untuk memenuhi kebutuhan interaksi antara siswa dan membantu orang atau siswa yang terlibat dalam suatu tugas bersama.

Mind Mup 2.0 adalah groupware yang digunakan untuk mengorganisasikan informasi dalam bentuk mind map dengan teknik kolaboratif secara sinkronous serta berbasis teknologi cloud storage Google Drive, untuk menyimpan artifak atau hasil kerja kolaboratif. Dengan MindMup 2.0, siswa bergabung bersama, menggabungkan ide dengan teman yang lain tanpa kehilangan pengetahuan pribadi tentang topik. Bahkan, ide sesama siswa dapat dipadukan, saling melengkapi dan karena dilakukan berkelompok tentu berbagi pengetahuan menjadi sangat menyenangkan bagi siswa. 
Oleh karena itu, sebagai sebuah alternatif dalam pengorganisasian informasi, diperlukan pembahasan untuk mengetahui : 1) bagaimana teknik pemanfaatan fitur-fitur dalam lingkungan kerja MindMup 2.0 untuk membuat mind map topik elektronika, 2) bagaimana unjuk kerja MindMup 2.0 saat dilakukan akses data yang sama secara multi user untuk 1 kelompok kecil yang terdiri dari empat siswa, 3) bagaimana teknik penyimpanan artifak atau hasil kerja kolaboratif tersebut.

\section{PEMBAHASAN}

\section{Pembelajaran Kolaboratif}

Pembelajaran kolaboratif adalah suatu metode pengajaran dan pembelajaran dimana suatu kelompok siswa secara bersama mengeksplorasi suatu pertanyaan atau suatu tugas bermakna (Educational Broadcasting Corporation, 2004). Pembelajaran kolaboratif berbeda dari pembelajaran tradisional dimana pembelajaran kolaboratif lebih menekankan aktifitas siswa dengan pendekatan bekerja sama dibanding berkompetisi secara individual satu sama lain. Siswa bekerja bersama dalam kelompok atau kelompok kecil dengan suatu aktifitas terstruktur, terpandu oleh tujuan yang jelas sehingga dapat meningkatkan pemahaman siswa terhadap objek yang dieksplorasi. Beberapa hal yang harus diperhatikan pada proses pembelajaran kolaboratif adalah

a. Siswa harus merasa aman tetapi tertantang

b. Tugas yang dikerjakan bersama tersebut harus terdefinisikan dengan jelas

c. Kelompok harus cukup kecil untuk memastikan bahwa setiap siswa dapat berkonstribusi

Pembentukan kelompok dapat ditetapkan berbasis kemampuan atau pendekatan campuran (mixed-skilled), dimana hal ini biasanya bergantung pada tujuan pembelajaran guru. Sedangkan dari sisi jumlah, Slavin dalam Educational Broadcasting Corporation (2004), menjelaskan bahwa kelompok 
dengan jumlah dua atau tiga orang akan lebih produktif dibanding empat atau lebih.

\section{Mind Map}

Calfee dkk (2004) menyebutkan bahwa ketrampilan siswa dalam mengorganisasikan pengetahuan atau informasi (organizing) merupakan salah satu elemen penting dari kesatuan fungsi proses pembelajaran yang meliputi menghubungkan (connecting), mengorganisasikan (organizing), memikirkan kembali konsep yang dipelajarai (reflecting) dan memperluas pengetahuan (extending). Informasi penting bagi pembentukan ilmu pengetahuan dan siswa perlu belajar tentang bagaimana mengatur dan mengelola informasi yang diterimanya dalam pembelajaran.

Masih menurut Calfee dkk (2004), ada beberapa cara menfasilitasi siswa dalam mengorganisasikan informasi, salah satunya, guru dapat meminta siswa melakukan pengorganisasian secara grafis melalui teknik mencatat yaitu penulisan informasi dengan tangan, baik sebelum, selama atau sesudah belajar. Pada tahun 1970-an seorang ahli Otak dan Pembelajaran, Tony Buzan, memperkenalkan teknik grafikal dalam pengorganisasian informasi yang diberi nama mind map atau peta pikiran. Menurut Buzan,

"A mind map is a powerful graphics technique which provides a universal key to unlock the potensial of the brain. It harnesses the full range of cortical skills - word, image, number, logic, rhythm, colour and spatial awareness- in a single, uniquely powerfull manner. In so doing, it gives you the freedom to roam the infinitive expanses of your brain. The mind map can be applied to every aspect of life where improved learning and clearer thinking will enhance human performance". 


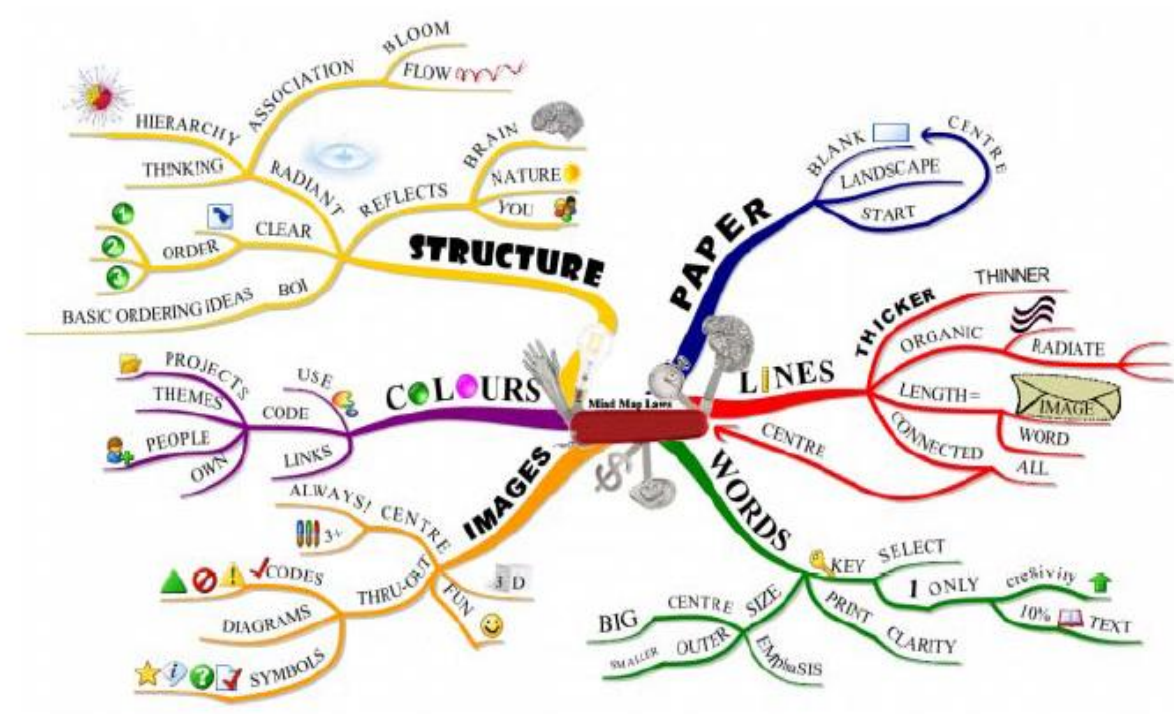

Gambar 1. Mind Map® dari Law of Mind Map

Sebagai teknik grafikal, mind map menyediakan kunci universal untuk membuka potensi dari otak karena menggunakan seluruh "cortical-skills" kata, gambar, angka, logika, ritme, warna dan kesadaran spasial, yang semuanya dalam cara yang unik. Mind map dapat digunakan dalam seluruh aspek kehidupan manusia.

Dalam membuat Mind Map, Tony Buzan dalam Djohan Yoga (2016) menetapkan sejumlah aturan teknis atau Law of Mind Map yang harus diikuti agar Mind Map bermanfaat secara maksimal. Adapun aturan tersebut sebagai berikut

a. Menggunakan kertas polos dan menuliskan pusat topik pada bagian tengah kertas

b. Menggunakan garis dalam menjelaskan detail topik dengan cara menarik garis-garis dengan arah menjauh dari pusat garis

c. Menggunakan kata kunci untuk menjelaskan informasi

d. Menggunakan sebanyak mungkin gambar agar lebih menarik, mudah diingat dan mudah dipahami

e. Menggunakan warna, minimal 3 warna, lebh baik 5-6 warna 
f. Menggunakan struktur radian dengan pusat topik di tengah kertas

Berdasarkan aturan teknis tersebut, proses pembuatan mind map dilakukan dengan empat langkah berurutan (Djohan Yoga, 2016):

a. Menentukan topik utama (Central Topic).

b. Membuat sub-sub yang akan dipelajari atau cabang dari topik utama tersebut. Penggambaran sub-sub ini disebut Basic Ordering Ideas (BOIs). Pembuatan sub-sub tersebut berpedoman pada prinsip $5 \mathrm{H}$ yaitu What, Why, Where, When, Who, dan How.

c. Melengkapi cabang dengan data atau informasi

d. Melengkapi setiap cabang dengan gambar, simbol, tabel, file sisipan (attachment) dsb.

Sesuai dengan tujuan bahwa mind map merupakan suatu cara yang dapat dipergunakan guru dalam menfasilitasi proses pengorganisasian informasi pada siswa, maka dalam proses pembelajaran (Djohan Yoga, 2016), mind map dapat dipergunakan pada bagian awal, tengah ataupun akhir pembelajaran seperti:

a. Overview adalah tinjauan menyeluruh terhadap suatu topik pada saat proses pembelajaran baru saja dimulai yang bertujuan memberi gambaran umum pada siswa tentang topik yang akan dibicarakan.

b. Preview atau tinjauan awal merupakan lanjutan dari overview dimana gambaran umum yang diberikan lebih detail dan dapat berupa penjabaran lebih lanjut dari silabus.

c. Inview adalah tinjauan mendalam yang merupakan inti dari proses pembelajaran dimana suatu topik akan dibahas secara detail, terperinci dan mendalam.

d. Review merupakan tinjauan ulang yang dilakukan menjelang berakhirnya pembelajaran dan berupa ringkasan dari bahan yang telah diajarkan serta ditekankan pada informasi, konsep atau rumus penting yang harus 
dikuasai oleh siswa. Review membantu siswa untuk fokus dalam mempelajari ulang seluruh bahan yang diajarkan di sekolah.

\section{MindMup2.0 sebagai Groupware Berbasis Cloud Storage}

Trudy Johnson-Lens (1978) mendefinisikan groupware sebagai proses-proses kelompok secara sengaja ditambah perangkat lunak untuk mendukungnya. Pengertian lain menyebutkan bahwa groupware dimaksudkan sebagai suatu cara untuk berbagi dokumen atau rich-media yang memungkinkan terjadinya kolaborasi sehingga lebih efektif. Groupware atau perangkat lunak kolaboratif membantu menfasiliatsi tim yang berorientasikan tindakan bersama yang meliputi tiga bentuk:

a. Komunikasi, merupakan bentuk pertukaran informasi yang tidak terstruktur

b. Konferensi, berbentuk kerja interaktif untuk tujuan bersama. Contoh: curah pendapat atau voting.

c. Koordinasi, pekerjaan kompleks yang saling memiliki ketergantungan menuju tujuan bersama. Setiap orang memiliki tugas berbeda, setiap orang memiliki konstribusi.

MindMup merupakan aplikasi peta pikiran (mind mapping) yang terintegrasi dengan Google Drive serta bersifat realtime kolaboratif yang memungkinkan terjadinya kolaborasi dalam kelompok. Sebagai aplikasi kolaboratif, MindMup memungkinkan para pengguna mengorganisasikan dan memberikan pendapat dalam suatu area kerja dalam suatu topik yang sedang dibahas. Berkaitan dengan visualisasi peta pikiran, pada mind mup, tiap peserta yang terlibat dapat saling menambahkan cabang / sub / penjelas topik sehingga tampak sebagai keterhubungan visual dalam suatu topik utama.

Selain mengakomodasi kerja kolaboratif, MindMup juga memanfaatkan teknologi cloud storage yang terintegrasi dengan Google Drive sehingga memungkinkan artifak atau hasil kerja kolaboratif tersimpan 
secara online sebagai dokumen digital.Saat ini, media penyimpanan data digital sudah memasuki era baru. Perkembangan teknologi menawarkan media penyimpanan data secara online, dengan server virtual, yang dikenal dengan namaCloud Storage. Teknologi penyimpan digital ini tidak memerlukan lagi perangkat khusus offline, cukup berbekal perangkat atau gadget dengan dilengkapi layanan koneksi internet. Konsep baru ini menawarkan beberapa sisi baik seperti skalabilitas, yaitu peningkatan daya tampung sesuai kebutuhan baik dengan penambahan perangkat atau memilih layanan berbayar; aksesibilitas, yaitu data yang disimpan dapat diakses kapanpun, dimanapun asalkan terhubung dengan internet; dan keamanan yaitu menghindari kehilangan data saat perangkat atau gadget yang kita miliki rusak.

Saat ini, perkembangan telah sampai pada dukungan teknologi penyimpan digital dalam memenuhi kebutuhan interaksi atau kerja bersama atau kolaborasi dan sampai pada kemampuan melakukan penyimpanan artifak atau hasil kerja kolaboratif. MindMup dapat diakses pada alamat http://www.mindmup.com untuk MindMup versi 1.0 atau http://drive.mindmup.com untuk MindMup versi 2.0.

\section{Mind Map memanfaatkan MindMup 2.0}

Pemanfaatan MindMup 2.0 untuk pembuatan mind map kolaboratif adalah sebagai berikut:

\section{a. Persiapan Sumber Belajar dan Pengelolaan Pembelajaran}

Pemanfaatan MindMup 2.0 diawali beberapa langkah persiapan baik berkaitan dengan sumber belajar maupun desain pengelolaan pembelajaran.

\section{Sumber Belajar}

Berkaitan dengan sumber belajar, hal yang perlu dipersiapkan adalah:

1) Menyediakan perangkat komputer yang terkoneksi dengan internet 
2) Setiap pengguna/ siswa memiliki akun Gmail (layanan surat elektronik milik Google). Jika siswa dibentuk dalam kelompok/ kelompok kecil, maka tiap siswa dalam kelompok/ kelompok kecil harus memiliki akun Gmail.

3) Mengakses MindMup melalui internet pada alamat http://www.mindmup.com untuk MindMup versi 1.0 atau http://drive.mindmup.com untuk MindMup versi 2.0.Kajian ini menggunakan MindMup versi terbaru, yaitu MindMup 2.0 yang diakses melalui http://drive.mindmup.com

\section{Desain Pengelolaan Pembelajaran}

Pemanfaatan MindMup 2.0 digunakan pada sesi preview dalam mata kuliah Elektronika, topik cabang ilmu elektronika. Desain pembelajaran dibuat dengan langkah-langkah sebagai berikut:

1) Guru membuka pelajaran

2) Dengan metode ceramah berbasis media presentasi Guru menyampaikan materi tentang cabang ilmu elektronika

3) Guru membagi kelas menjadi kelompok kecil, dimana tiap kelompok terdiri dari 4siswa

4) Guru memberikan tugas bermakna pada tiap kelompok berupa penjabaran kembali materi cabang ilmu elektronika yang telah disampaikan dengan menggunakan mind map. Penjabaran dengan mind map ini bermanfaat meringkas materi panjang yang disampaikan Guru dengan lebih ringkas sehingga siswa memahami keseluruhan materi dalam waktu yang lebih singkat. Serta dengan teknik grafikal, diharapkan, ringkasan akan mudah dipahami dan mudah diingat.

Adapun dokumentasi sub topik cabang Ilmu Elektronika dalam rancangan MindMup adalah sebagai berikut: 
Tabel 1. Cabang ilmu elekronika (berbagai sumber, 2016) dalam desain MindMup

\begin{tabular}{|c|c|c|c|}
\hline Cabang & Ruang lingkup & $\begin{array}{l}\text { Karakteristik / } \\
\text { Jenis }\end{array}$ & $\begin{array}{c}\text { Desain } \\
\text { MindMup }\end{array}$ \\
\hline $\begin{array}{l}\text { Elektronika } \\
\text { Analog } \\
\text { (Analogue } \\
\text { Electronic) }\end{array}$ & $\begin{array}{l}\text { Bidang elektronika } \\
\text { yang berkaitan } \\
\text { dengan } \\
\text { pengelolaan isyarat } \\
\text { analog, dengan } \\
\text { amplitudo dan } \\
\text { frekuensi sebagai } \\
\text { dua parameter } \\
\text { penting }\end{array}$ & $\begin{array}{l}\text { Modulasi sebagai } \\
\text { metode dalam } \\
\text { proses perubahan } \\
\text { dan pembawaan } \\
\text { sinyal, dengan tiga } \\
\text { variabel sebagai } \\
\text { dasar modulasi. } \\
\text { 1. Modulasi } \\
\text { Amplitudo } \\
\text { 2. Modulasi } \\
\text { Frekuensi } \\
\text { 3. Modulasi Fasa }\end{array}$ & $\begin{array}{l}\text { Sub Topik } \\
\text { (Child Node) } \\
\text { BOIs dua } \\
\text { tingkat } \\
\text { Warna merah } \\
\text { Jumlah } \\
\text { gambar } 1\end{array}$ \\
\hline $\begin{array}{l}\text { Elektronika } \\
\text { Digital } \\
\text { (Digital } \\
\text { Electronic) }\end{array}$ & $\begin{array}{l}\text { Bidang elektronika } \\
\text { yang berkaitan } \\
\text { dengan } \\
\text { pengelolaan sinyal } \\
\text { digital, yaitu sinyal } \\
\text { yang } \\
\text { direpresentasikan } \\
\text { dengan dua kondisi } \\
1 \text { (active, high, } \\
\text { true) atau } 0 \\
\text { (nonactive, low, } \\
\text { false) }\end{array}$ & $\begin{array}{lr}\text { Sistem } & \text { Digital } \\
\text { terdiri dari } & \text { sistem } \\
\text { kombinasional } \\
\text { (Combinational) } \\
\text { dan sistem } & \text { berurut } \\
\text { (Sequential). } & \text { Sistem } \\
\text { berurut } & \text { terbagi } \\
\text { menjadi } & \text { sistem } \\
\text { sinkron } & \text { dan } \\
\text { asinkron. } & \end{array}$ & $\begin{array}{l}\text { Sub Topik } \\
\text { (Child Node) } \\
\text { BOIs dua } \\
\text { tingkat } \\
\text { Warna } \\
\text { kuning } \\
\text { Jumlah } \\
\text { gambar } 1\end{array}$ \\
\hline Microelectronic & $\begin{array}{l}\text { Mikroelektonika } \\
\text { mencakup } \\
\text { pembahasan } \\
\text { tentang proses } \\
\text { industri dan desain } \\
\text { komponen } \\
\text { elektronika } \\
\text { berukuran kecil / } \\
\text { sangat kecil }\end{array}$ & - & $\begin{array}{l}\text { Sub Topik } \\
\text { (Child Node) } \\
\text { Warna } \\
\text { Oranye } \\
\text { Jumlah } \\
\text { gambar } 1\end{array}$ \\
\hline Circuit Design & $\begin{array}{l}\text { Membahas tentang } \\
\text { langkah-langkah } \\
\text { dalam siklus } \\
\text { perancangan } \\
\text { rangkaian }\end{array}$ & $\begin{array}{l}\text { Terdapat dua jenis } \\
\text { perancangan yaitu } \\
\text { circuit design dan } \\
\text { logic design }\end{array}$ & $\begin{array}{l}\text { Sub Topik } \\
\text { (Child Node) } \\
\text { BOIs satu } \\
\text { tingkat } \\
\text { Warna Ungu }\end{array}$ \\
\hline
\end{tabular}




\begin{tabular}{|c|c|c|c|}
\hline & elektronika & & $\begin{array}{l}\text { Jumlah } \\
\text { gambar 1 }\end{array}$ \\
\hline $\begin{array}{l}\text { Integrated } \\
\text { Circuit }\end{array}$ & $\begin{array}{l}\text { Membahas tentang } \\
\text { teknologi integrasi } \\
\text { komponen }\end{array}$ & $\begin{array}{l}\text { Berdasarkan skala } \\
\text { intergrasinya, } \\
\text { terdapat jenis-jenis } \\
\text { komponen } \\
\text { - SSI, MSI, LSI } \\
\text { - VLSI } \\
\text {-ULSI, WSI, SOC, } \\
\text { 3D-IC }\end{array}$ & $\begin{array}{l}\text { Sub Topik } \\
\text { (Child Node) } \\
\text { BOIs satu } \\
\text { tingkat } \\
\text { Warna merah } \\
\text { Jumlah } \\
\text { gambar } 1\end{array}$ \\
\hline $\begin{array}{l}\text { Optoelektronika } \\
\text { (Optoelektronic) }\end{array}$ & $\begin{array}{l}\text { Cabang } \\
\text { elektronika yang } \\
\text { mengkaji peralatan } \\
\text { elektronik yang } \\
\text { berhubungan } \\
\text { dengan cahaya }\end{array}$ & $\begin{array}{l}\text { Contoh penerapan: } \\
\text { - Komunikasi fiber } \\
\text { optik } \\
\text { - Sistem laser } \\
\text { - Sistem sensor } \\
\text { remote } \\
\text { - Sistem informasi } \\
\text { optik } \\
\text { - Sistem diagnosis } \\
\text { medis } \\
\end{array}$ & $\begin{array}{l}\text { Sub Topik } \\
\text { (Child Node) } \\
\text { Warna Hijau } \\
\text { Attachment } \\
\text { file } 1\end{array}$ \\
\hline $\begin{array}{l}\text { Semiconduktor } \\
\text { Devices }\end{array}$ & $\begin{array}{l}\text { Membahas tentang } \\
\text { komponen- } \\
\text { komponen dengan } \\
\text { basis teknologi } \\
\text { bahan } \\
\text { semikonduktor }\end{array}$ & $\begin{array}{l}\text { Macam-macam } \\
\text { komponen berbasis } \\
\text { komposisi jenis } \\
\text { bahan } \\
\text { semikonduktor } \\
\text { (N/P): } \\
\text {-Dua terminal } \\
\text { - Tiga terminal } \\
\text {-Empat terminal }\end{array}$ & $\begin{array}{l}\text { Sub Topik } \\
\text { (Child Node) } \\
\text { Warna Ungu } \\
\text { Jumlah } \\
\text { gambar } 3\end{array}$ \\
\hline $\begin{array}{l}\text { Embedded } \\
\text { Systems }\end{array}$ & $\begin{array}{lr}\text { Semacam } & \text { sistem } \\
\text { komputer } & \text { dengan } \\
\text { fungsi } & \text { yang } \\
\text { didedikasikan } \\
\text { secara luas pada } \\
\text { sistem reknik } \\
\text { maupun merstem } \\
\text { kelistrikan dengan } \\
\text { basis kerja real } \\
\text { time }\end{array}$ & $\begin{array}{l}\text { Berdasarkan basis } \\
\text { pemrosessannya } \\
\text { terdapat dua jenis } \\
\text { - Mikrokontroller } \\
\text { - Mikroprocessor }\end{array}$ & $\begin{array}{l}\text { Sub Topik } \\
\text { (Child Node) } \\
\text { BOIs dua } \\
\text { tingkat } \\
\text { Warna Hijau } \\
\text { Attachment } \\
\text { file 1 }\end{array}$ \\
\hline
\end{tabular}




\section{b. Teknik Pemanfaatan MindMup 2.0 untuk Mind Map}

Pemanfaatan MindMup 2.0 memerlukan persiapan sumber daya serta alokasi penerapan sesuai desain pengelolaan pembelajaran yang ditetapkan Guru. Berdasarkan pembahasan sebelumnya, MindMup 2.0 diterapkan pada sesi preview yang berisi penjelasan detail topik cabang ilmu elektronika. Sesuai desain pengelolaan pembelajaran, setelah Guru menyampaikan materi, selanjutnya Guru menetapkan siswa dalam kelompok kecil berjumlah empat siswa, merujuk pada pendapat Slavin bahwa kelompok dengan jumlah dua atau tiga orang akan lebih produktif dibanding empat atau lebih.

Menurut Tony Buzan, pembuatan Mind Map harus memperhatikan aturan dalam Law of Mind Map agar diperoleh dokumen peta pikiran yang optimal. Groupware Mind Mup 2.0 memberikan dukungan pembuatan Mind Map sesuai Law of Mind Map.Adapun adalah langkah-langkah pembuatan Mind Map dengan groupwareMind Mup 2.0 pada topik cabangilmu elektronika adalah sebagai berikut:

1) Siswa / pengguna menyiapkan akun Gmaildan login pada akun tersebut.

2) Mengakses MindMup 2.0 pada alamat http://drive.mindmup.com. Untuk memulai pembuatan MindMup akan tampil 2 pilihan cara: CREATE A NEW MAP atau OPEN FROM GOOGLE DRIVE. Pilih Create a new map, jika menghendaki pembuatan baru atau masuk secara langsung pada area MindMup. Pilih Open From Google Drive, jika menghendaki membuka dokumen yang pernah dibuat atau masuk pada MindMup melalui fitur MindMup 2.0 for Google Drive.

3) Pilihan Create a new map akan memberikan tampilan lingkungan kerja MindMup dengan center noded itengah untuk menuliskan topik utama seperti ditunjukkan gambar 2. 


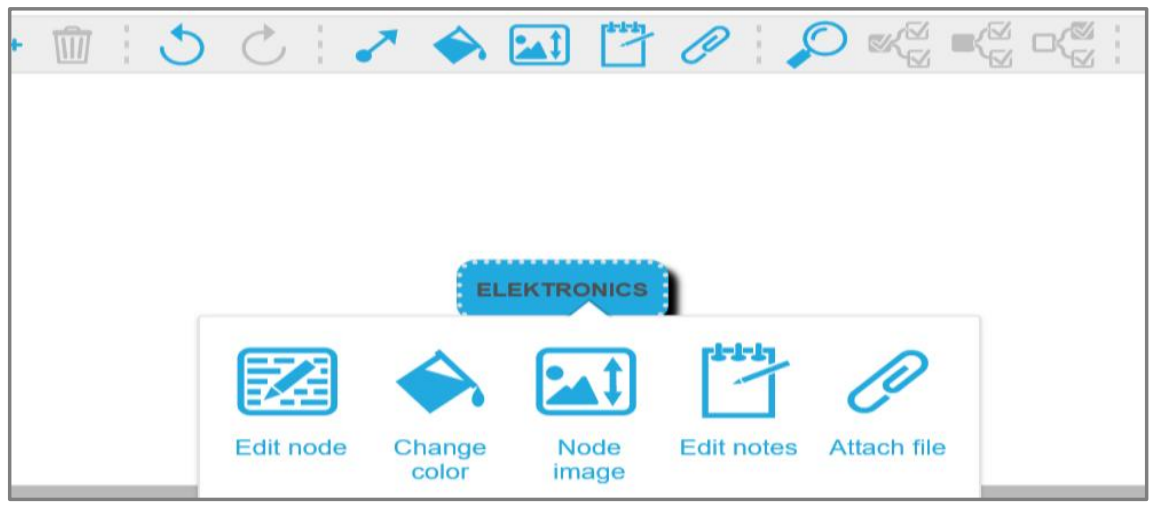

Gambar 2. Lingkungan kerja dan center node pada MindMup 2.0

4) Aturan pertama, menuliskan topik utama di bagian tengah dokumen (Center Node). Sebagi contoh, double klik pada center node berwarna biru, ketikkan topik Electonics. Untuk pengelolaan lanjut, klik kanan node dan lakukan Edit Node, Change Color, Node Image, Edit Notes, atau Attach File.

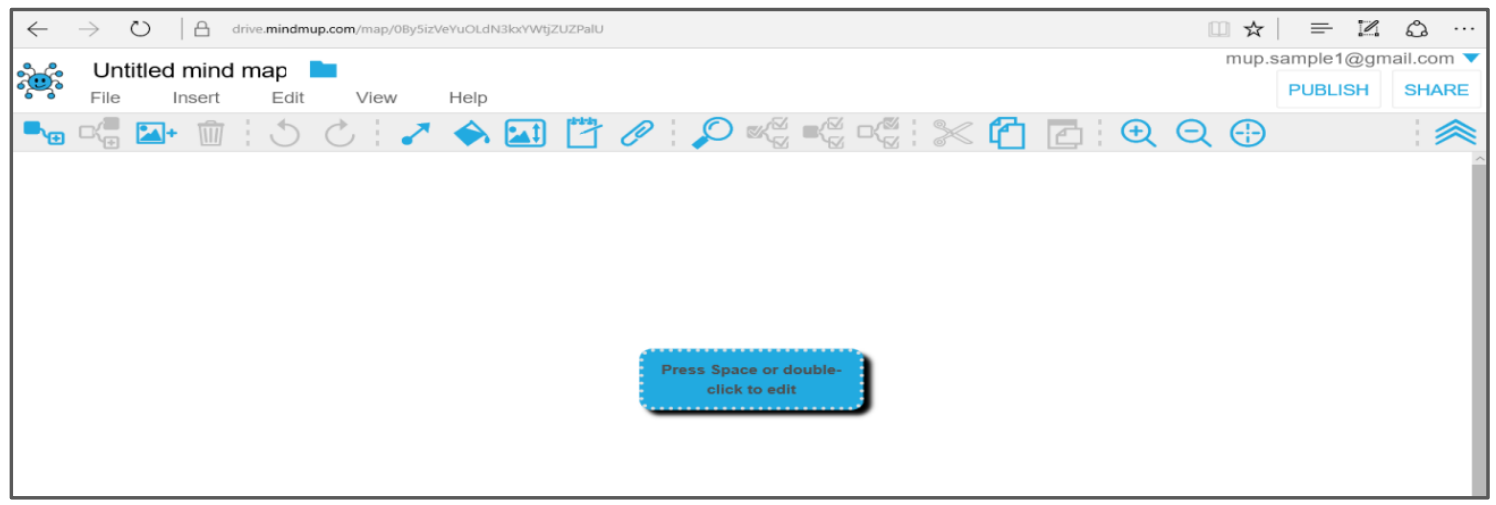

Gambar 3. Aturan pertama penempatan topik utama di Center Node

5) Aturan kedua, membuat cabang / sub topik / child node dari topik utama. Cara menambah sub topik adalah dengan pilih node topik utama, kemudian pilih icon "Insert child node" pada menu bar untuk membuat sebuah node untuk sub topik. Untuk yang pertama, buat sub topik Semiconductor Devices. Sub topik dapat dibuat menjadi sub-sub topik berikutnya sesuai aturan BOIs. Buat sub topik yang lain dengan mengacu Tabel 1. 


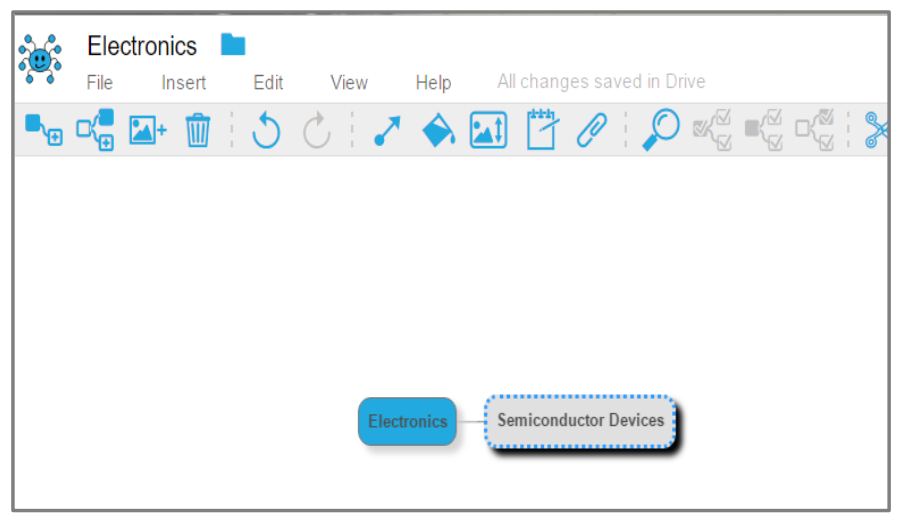

Gambar 4. Sub Topik (Child Node)

6) Aturan ketiga, menuliskan kata kunci pada tiap node. Peta pikiran terdiri dari rangkaian topik utama dan sub topik dalam struktur radian. Topik utama dan sub topik ditulis dengan suatu kata kunci sebagai data atau informasi. Contoh sub topik dalam tugas bermakna ini adalah Semiconductor Devices, Digital Electronics, Analogue Electronics, dst sesuai Tabel 1.

7) Aturan keempat, menempatkan gambar pada node. Law of Mind Map merekomendasikan penggunaan gambar untuk menjelaskan node. Gambar memberi kesan lebih menarik, lebih bermakna dan mudah dipahami dalam penyampaian informasi. Untuk mempermudah, gambarbisa diakses dari Google Photos dalam drive. Gambar 5 menunjukkan contoh penyisipan gambar.

8) Aturan kelima, penggunaan warna. Law of Mind Map merekomendasikan penggunaan warna pada node, dengan jumlah 3 sampai 5 jenis. Penggunaan warna akan memberi pengaruh pada stimulus otak serta memberi kesan menarik. Pada tugas bermakna ini digunakan 5 variasi warna disertai penyisipan attachment file pada beberapa sub topik. 


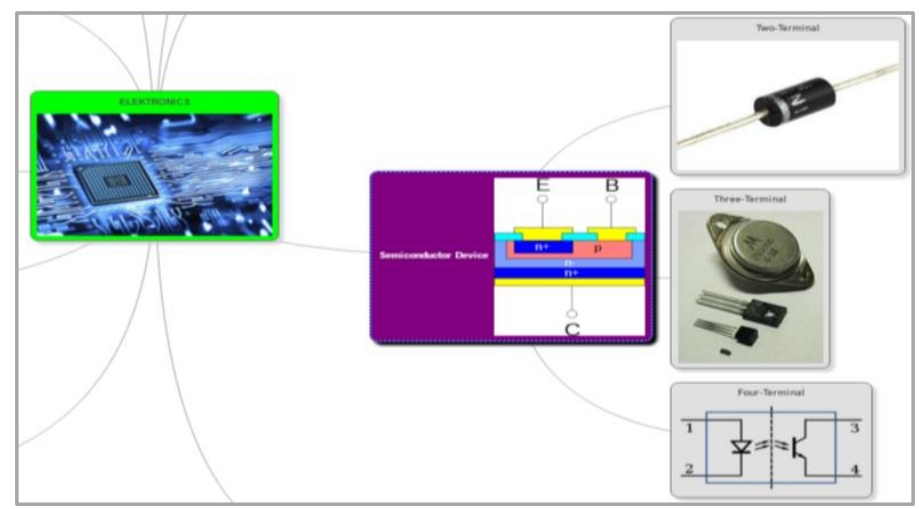

Gambar 5. Penyisipan gambar dan pemberian warna

9) Aturan keenam, mengatur posisi topik dan sub topik dalam area dengan struktur radian.Struktur radian diwujudkan dengan pembuatan mind map dari titik tenga area kerja MindMup dan ditarik kesamping dalam segala arah.

\section{c. MindMup 2.0 untuk akses data multiuser}

Pemanfaatan MindMup 2.0 mengakomodasi kerja kolaboratif dari siswa yang diorganisasikan dalam kelompok / kelompok kecil.Berikut adalah unjuk kerja Mind Mup 2.0 yang memberikan dukungankerja kolaboratif / multiuser secara sinkronous.

1) Siswa menyelesaikan tugas bermakna mind map dalam kelompok kecil, sebagai contoh dalam satu kelompok terdiri dari 4 siswa.

2) Tiap siswa dalam kelompok memiliki akun Gmail sebagai berikut:

\begin{tabular}{|l|l|}
\hline Siswa & $\begin{array}{l}\text { Contoh Akun layanan surat elektronik } \\
\text { Google }\end{array}$ \\
\hline Siswa 1 & mup.sample1@gmail.com \\
\hline Siswa 2 & mup.sample2@gmail.com \\
\hline Siswa 3 & mup.sample3@gmail.com \\
\hline Siswa 4 & mup.sample4@gmail.com \\
\hline
\end{tabular}

3) Selanjutnya, salah satu siswa (Siswa 1) mengawali pembuatan mind map dalam MindMup 2.0 dengan mengakses laman https://drive.mindmup.com/. Setelah area kerja MindMup terbuka, Siswa 1 memulai kerja kolaboratif dengan cara membagi dokumen mind map 
kepada siswa lain (Siswa 2, Siswa 3 dan Siswa 4). Caranya, Siswa 1 menekan tombol SHARE (pojok kanan atas area MindMup), maka akan tampil isian yang meminta Siswa 1 memasukkan akun Gmail Siswa 2, 3 dan 4.

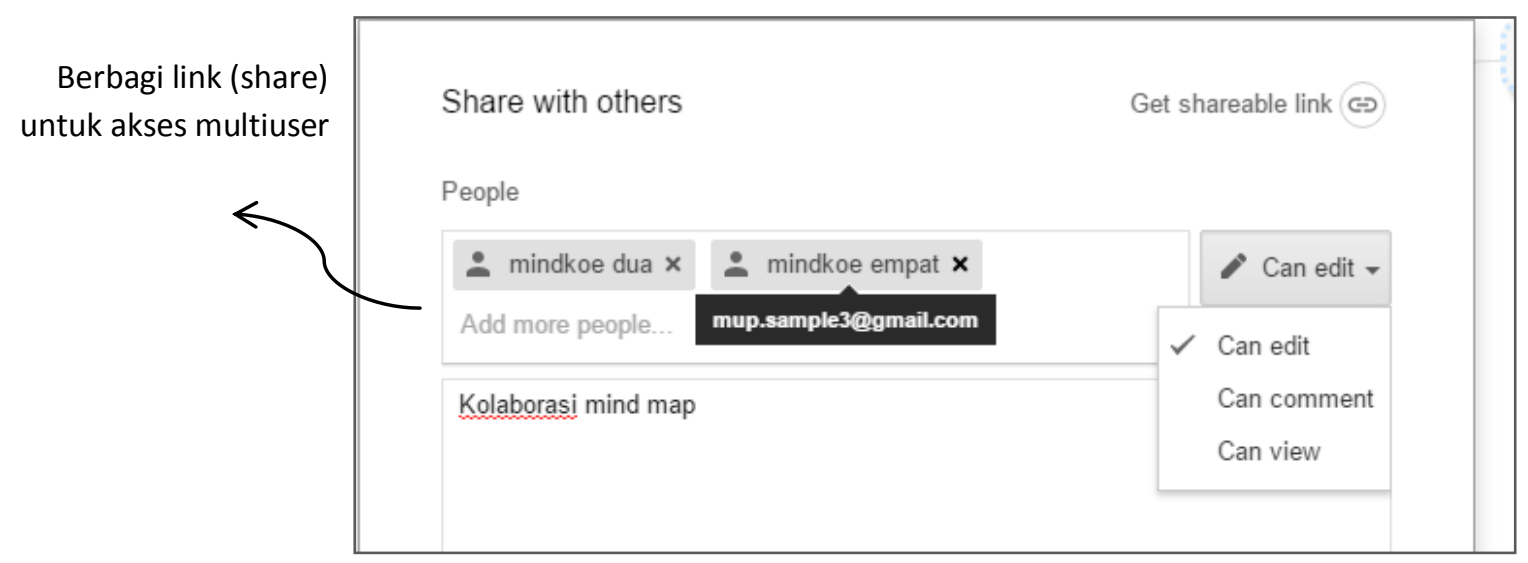

Gambar 6. Antarmuka untuk mengirim link akses multiuser dan sinkronous

4) Pada saat bersamaan, dengan asumsi akses komunikasi data berjalan stabil, Siswa 2, 3 dan 4 akan menerima link untuk memulai akses dokumen mind map yang telah dibagi oleh Siswa 1 secara kolaboratif dan sinkronous. Dokumen kolaboratif dapat pula diakses melalui link "Shared with me".

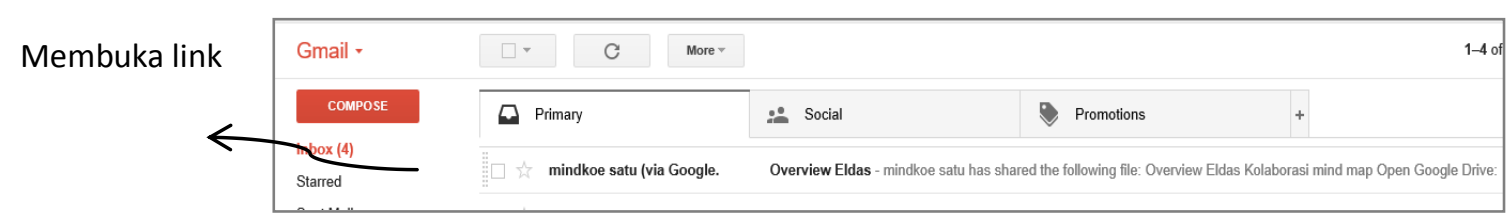

Gambar 7. Link untuk membuka akses bersama

5) Klik pada link, pilih Open atau Overview. Selanjutnya tampil link untuk membuka dokumen mind map melalui "MindMup 2.0 For Google Drive".

Selanjutnya, tugas bermakna mind map sudah dapat diakses secara bersama / kolaboratif / sinkronous. 
6) Zero Friction

Perubahan mind map akibat perilaku salah seorang siswa akan menyebabkan perubahan secara sinkronous pada mind map siswa yang lain pada waktu yang sama.

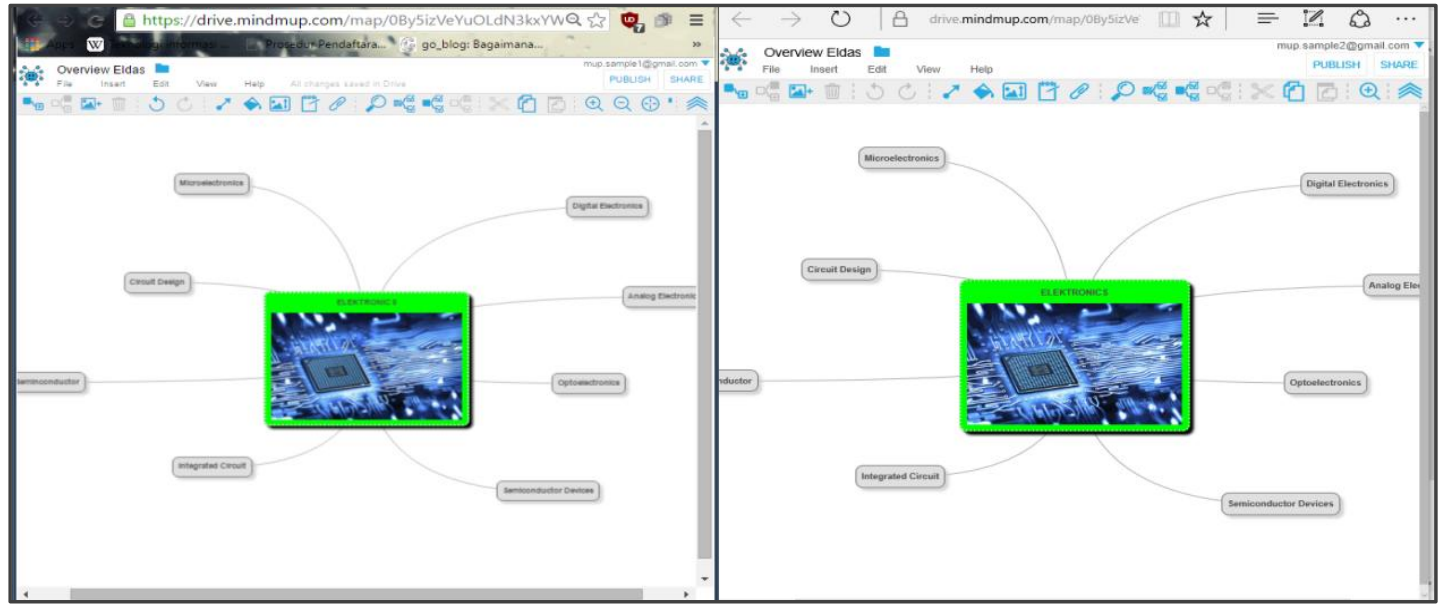

Gambar 8.Tampilan sinkronous tanpa friksi pada dua siswa

\section{d. Teknik Penyimpanan Artifak / Hasil Kerja Kolaboratif}

Selain proses kolaboratif, MindMup 2.0 mendukung penyimpanan artifak / hasil kerja kolaboratif secara online dengan teknologi cloud storage Google yaitu Google Drive. Proses penyimpanan online terjadi dengan unjuk kerja sebagai berikut:

1) Menyimpan hasil kerja secara otomatis (Autosave Works). Saat pengguna membuat mind map dengan MindMup,secara realtimeinstance hasil kerja mind maptersimpan dalam Google Drive.

2) Manajemen dokumen dalam drive. Manajemen dilakukan agar hasil kerja kolaboratif tersimpan dan terkelola dengan baik,serta mudah diakses saat diperlukan. Manajemen drive dilakukan dengan membuat folder dalam drive. 


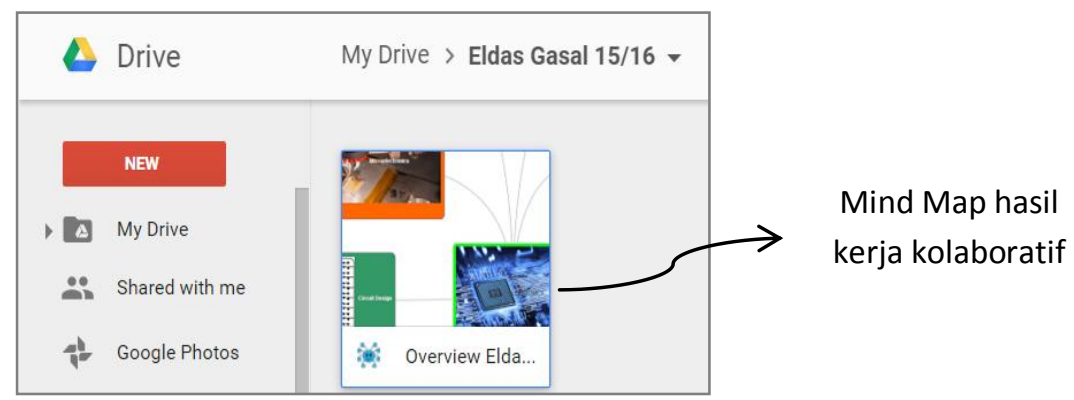

Gambar 9. Manajemen Dokumen Hasil Kerja dalam Drive

3) Sinkronisasi penyimpanan antara drive dengan perangkat lain. Dengan fasilitas "Get Drive for PC" dari Google, drive dapat disinkronkan dengan perangkat apa saja ( $P C$, tablet, mobile) sehingga hasil kerja kolaboratif dalam drive dapatdiakses kapan sajadan dimana saja.

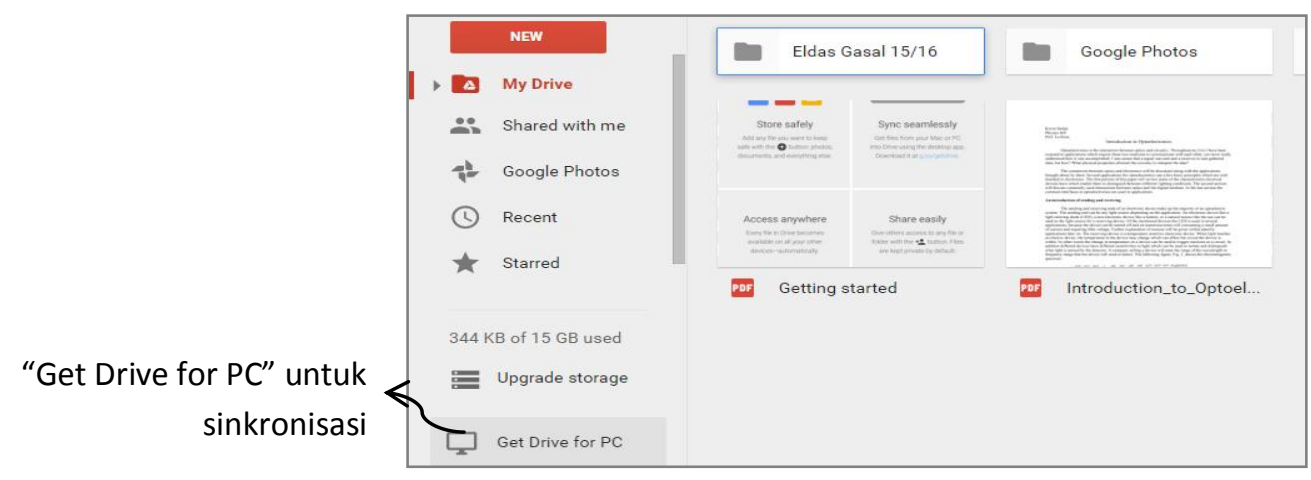

Gambar 10.Fitur untuk Sinkronisasi

\section{KESIMPULAN}

Berdasarkan pembahasan dapat disimpulkan bahwa:

1. Pembuatan mind map pada tugas bermakna topik cabang elektronika memanfaatkan MindMup 2.0 dilakukan dengan langkah-langkah sesuai aturan Law of Mind Map yang meliputi penulisan topik utama, penambahan sub topik, penulisan informasi dengan kata kunci, pemberian gambar, pemberian warna, serta pembuatan topik dan sub topik dalam struktur radian. 
2. MindMup 2.0 mendukung kerja kolaboratif dengan cara membagi akses dokumen melalui link akun layanan surat elektronik Google. Kerja kolaboratif dilakukan secara sinkronous tanpa friksi.

3. Penyimpanan artifak atau hasil kerja kolaboratif dilakukan dengan teknologi cloud storage, Google Drive. 


\section{DAFTAR PUSTAKA}

Dix et al., 2004, Human-Computer Interaction(3rd ed.), London: Pearson Education Limited.

Djohan Yoga, (n.d), Applied Real Time Mind Map® @ Classroom, 17 Maret 2016, http://www.paxhigh.com/doc/applied_rt-mm.pdf

Educational Broadcasting Corporation, 2004, Cooperative and Collaborative Learning, $1 \quad$ Pebruari 2016 , http://www.thirteen.org/edonline/concept2class/

Electronics, 1 Pebruari 2016, https://en.wikipedia.org/wiki/Electronics

Elizabeth M. Riddle, 1999, Lev Vygotsky's Social Development Theory, 10 Maret 2016,

http://members.iinet.net.au/ aamcarthur/4_Mar_2008_files/Vygotskys_S ocial_Development_Theory.pdf

MindMup 1.0, 28 Desember 2015, https://www.mindmup.com/

MindMup for Google Drive, 1 Maret 2016, https://drive.mindmup.com/

Rachmi Noor Hanifah, 2015, "Penggunaan Concept Map dan Mind Map untuk Mengembangkan Kemampuan Penalaran dan Penguasaan Konsep”,dalam Prosiding KPSDA, Volume 1, Nomor 1, Surakarta: FKIP, UNS.

Roxanne G.M dan R.C. Calfee, 2004, Making Thinking Visible, 1 Pebruari 2016, http://science.nsta.org/enewsletter/2005-11/sc0411 20.pdf

Sarasota Manathee, 2014, MindMup, Sarasota: University of South Florida.

Tony Buzan, 2012, The Ultimate Book of Mind Maps ${ }^{\circledR}$, London: Thorsons, Harper Collins Pulisher.

Trudy Johson-Lenz, 1978, Collaborative Software, 17 Maret 2016,https://en.wikipedia.org/wiki/Collaborative_software 